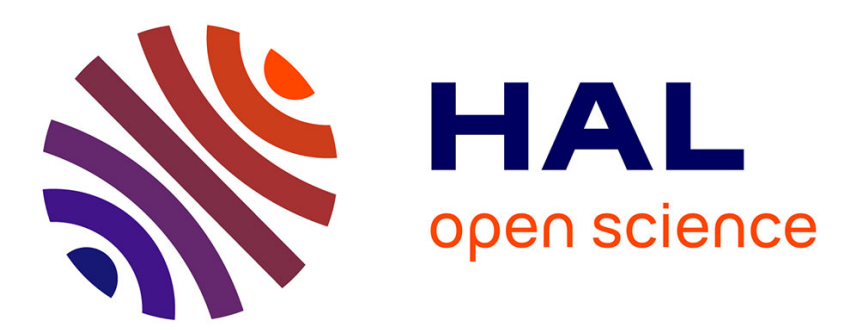

\title{
Relativism or Anti-Anti-Relativism? Epistemological and Rhetorical Moves in Feminist Epistemology and Philosophy of Science
}

Kathrin Hönig

\section{- To cite this version:}

Kathrin Hönig. Relativism or Anti-Anti-Relativism? Epistemological and Rhetorical Moves in Feminist Epistemology and Philosophy of Science. European Journal of Women's Studies, 2005, 12 (4), pp.407-419. 10.1177/1350506805057098 . hal-00571253

\section{HAL Id: hal-00571253 \\ https://hal.science/hal-00571253}

Submitted on 1 Mar 2011

HAL is a multi-disciplinary open access archive for the deposit and dissemination of scientific research documents, whether they are published or not. The documents may come from teaching and research institutions in France or abroad, or from public or private research centers.
L'archive ouverte pluridisciplinaire HAL, est destinée au dépôt et à la diffusion de documents scientifiques de niveau recherche, publiés ou non, émanant des établissements d'enseignement et de recherche français ou étrangers, des laboratoires publics ou privés. 


\title{
Relativism or
}

\section{Anti-Anti-Relativism?}

\section{Epistemological and Rhetorical Moves in Feminist Epistemology and Philosophy of Science}

\author{
Kathrin Hönig
}

UNIVERSITÄT ZÜRICH

\begin{abstract}
Feminist approaches in epistemology and philosophy of science have frequently been labelled as 'relativist', both by feminist as well as by non-feminist philosophers. Regularly the so labelled distance themselves from even the mere suspicion of relativist tendencies. There is a remarkable discrepancy between an attributed and a self-declared relativism. Taking the self-declared relativism of Lorraine Code as an example, the article argues that it is a case of a rhetorical not epistemological relativism, better termed as anti-anti-relativism, but that there are nevertheless good reasons for feminists to follow Code along that path.
\end{abstract}

KEY WORDS epistemology $\bullet$ feminism $\bullet$ philosophy of science $\bullet$ relativism

Feminists 'might do well to "come out" and declare themselves relativists' the Canadian philosopher Lorraine Code writes in her essay 'Must a Feminist be a Relativist After All?' (Code, 1995: 186). This statement, however, makes her quite unique in the philosophical landscape, as writers in feminist epistemology and philosophy of science normally distance themselves from relativism. More precisely, they distance themselves even from the mere suspicion of relativist tendencies. On the one hand, the reason for this surely is to be sought in a dominant anti-relativist philosophical tradition, especially in philosophy of science. On the other hand, it has something to do with common attacks against the very idea of a feminist epistemology, attacks which rely on that philosophical tradition. Usually, there is no need for the anti-feminist opponents to bring in the big logical guns (charges of self-refutation of relativism for

European Journal of Women's Studies Copyright (C) 2005 SAGE Publications (London, Thousand Oaks and New Delhi), 1350-5068 Vol. 12(4): 407-419; DOI: $10.1177 / 1350506805057098$ 
instance), rather they may rely on the scientistic ideal of an abstract concept of knowledge that presupposes gender to be a factor of ideological impurities blurring the fact-value distinction: hence, something that threatens the achievement of politically neutral, universally valid, objective knowledge. These presupposed ideological impurities are thought to entail that the results of feminist scholarship do not and in fact cannot match the ideal of objectivity as conceived by the opponents and, therefore, are to be ignored or to be rejected. (See Lloyd [1996] for an extensive analysis of that kind of anti-feminist argument.) Generally, charges of relativism become, as Code puts it, a 'trump card' (Code, 1995: 187) dismissing every argument in favour of contextualizing, localizing or situating knowledge.

Given this background, feminist epistemology, so to say, had and still has two tasks. On the one hand, it has to ward off charges of relativism. On the other hand, it has to show that feminist scholarship can appeal to objectivity for its results with strong justification; at least one strand in feminist epistemology has claimed such objectivity. From this view, the concept of objectivity has undergone a semantic change from its idealized, normative and abstract formulation committed to strong value-neutrality to a far more descriptive concept, taking into consideration not only a given scientific practice and its production of scientific knowledge but also the context of discovery (as opposed to the context of justification), i.e. by and large the social context of science. (See the survey essay of Betzler, 1998; but also Barwell, 1994; Gorham, 1995; Lloyd, 1995.) For an example of this altered understanding of objectivity one could appeal to Sandra Harding's concept of 'strong objectivity', Donna Haraway's 'situated knowledges', Helen Longino's 'contextual empiricism' or Lynn Hankinson Nelson's 'feminist empiricism' (Harding, 1991, 1993, 1995; Haraway, 1991; Longino, 1990; Hankinson Nelson, 1990). The important and common point of those positions is that the concept of objectivity under (feminist) attack is understood as looking at the world from a point of nowhere - the 'God-trick' as Haraway calls it (Haraway, 1991: 189, 195) - and that this should be changed into a look from somewhere, where the 'some', precisely, has to be made transparent and to be included in the justification. This strand of feminist epistemology could be encapsulated under the programmatic title 'working for an improved or broader concept of objectivity' where gender as a relevant factor would quite naturally have its place. But this move has, in my opinion, not much to do with a straightforward relativist attitude. Of course, that is all the debate is about, and it has not come to an end yet. Moreover, there is no common consensus about it within either the feminist scientific community or the scientific community in a larger sense. The allegation of relativism to postpositivist positions, such as Kuhn's or Quine's, who certainly are not accountable for gender-sensitive intentions, is a case of attributed 
relativism outside the feminist field. In any case, as long as most of the adherents to the 'broader concept of objectivity' programme consider themselves to be realists of one (mitigated) form of realism or another and reject (radical) relativism, I am reluctant to consider the denial of strict value-neutrality, a prudent and careful incorporation of so-called external or contextual sociological factors into epistemic justification as a via regia towards relativism. ${ }^{1}$

So, assuming this framework of feminist epistemology is working towards a broader or improved concept of objectivity, let us ask: what reasons could there be to plead for relativism, as Lorraine Code does, instead of joining the 'broader concept of objectivity' programme? Because pleading for relativism implies a twofold task to accomplish, namely to claim and prove objectivity for the position and to ground it in spite of and against the anti-relativist critique as a reasonable position.

Taking Code as an example, I argue in this article that the reasons she gives in her essay are not sufficient for grounding a relativist position and that her claimed relativism would be more adequately described as a rhetorical gesture ending in an anti-anti-relativism; an anti-anti-relativism that is not reducible to epistemological relativism. The idea, going back to an argument developed by Clifford Geertz (1989), is that doubling the negative prefix 'anti' does not lead to a neutralization of that very prefix according to the law of double negation. Anti-anti-relativism, rather, is understood to represent a critique of certain forms of anti-relativism and a useful instrument in disarming overstated arguments concerning the negative consequences of relativism.

The main aim of this article is to contribute, via a critique of Code, to conceptual clarification and to explain the consequences and commitments following or rather not following from taking up a relativist stance à la Code. It will turn out that Code's rhetorical relativism, reinterpreted as anti-anti-relativism, can be classified into the aforementioned strand of feminist epistemology with its altered concept of objectivity. Conversely, anti-anti-relativism turns out to be highly recommendable to feminists.

Because of the notorious definitional difficulties, ${ }^{2}$ I abstain from giving an extensive definition of relativism. Roughly speaking, relativism should be understood as a position denying the possibility of unrelativized, universally valid claims (be they truth claims, moral claims or else). Instead, claims are understood to be justifiable only relative to a framework that provides the criteria of both intelligibility and justification. Depending on the sort of relativism in question, the framework itself is conceived as being either a conceptual, a theoretical, a cognitive, a moral, a cultural or other framework. To get a relativist position in the strict sense, the notion of a framework, however, is not sufficient. Moreover, there has to be something like the impossibility of privileging one framework over another in case of conflicting claims on the same subject matter, 
given that claims are considered justified relatively to their respective framework. In the literature, the impossibility of privileging a framework is termed 'incommensurability'. ${ }^{3}$ Frameworks are incommensurable, if questions about distributing bivalent truth-values between two conflicting claims fail to be conclusive.

Given this characterization of a relativist position, let me come back to Code's claim, that feminist epistemologists should subscribe to relativism. As I see it, there are two structurally different, however not clearly distinguished, clusters of arguments given by Code. One cluster is identifiable by its critique of the reductive scientistic ideal of certain - especially Anglo-American - forms of epistemology as Code perceives them. The other cluster is more diffuse and could best be characterized by a certain attitude of refusal, by a certain rebelliousness towards a discourse found to be hegemonic, and by the conscious provocation consisting in taking up a position considered unacceptable by others.

Whereas the first cluster, the cluster of critical reasons, as I would call them, clearly does not automatically imply relativism - after all, this is a form of critique very familiar to feminist approaches especially in the philosophy of science - the second cluster of reasons, the 'rebellious reasons', as I would like to call them, is more questionable. Does the disapproval of certain structures really lead to relativism? Does the refusal of the traditional epistemic concepts of objectivity and universalism that Code considers to be hegemonic imply an adherence to relativism? To answer those questions, let us take a closer look to Code's arguments. I start with her critique of the scientistically idealized epistemology. It is the kind of epistemology that has always attracted the feminist critique.

Epistemology traditionally centres around the threefold characterization of knowledge as true justified belief. Within that framework, philosophers usually work with the formula 'S knows that $p^{\prime}$, where $S$ represents a subject holding a belief, $\mathrm{p}$ the propositional content of that belief, and the verb 'to know' the relation under investigation, holding between the subject and the belief-content. In the relativism essay Code builds on a line of critical arguments developed earlier (Code, 1991) in pointing out that the ' $\mathrm{S}$ ' in the ' $\mathrm{S}$ knows that $\mathrm{p}$ ' formula is typically conceived as an abstract, ahistorical, disembodied and faceless subject of knowing. She emphasizes:

Since a theory of knowledge, as I conceive of it, should aim to inform and explicate practice - to determine how people can know and act within the specific symbolic, cultural, and social structures and institutions they inhabit, and to incorporate those understandings into its own articulation then what matters is the practical impact of any theoretical project, and its openness to modification, when practice reveals its shortcomings. (Code, 1995: 190-1) 
This emphasis on the practical aspects of a theory of knowledge is accompanied by a critique of scientism in epistemology. Epistemology, it is argued, takes its examples and paradigmatic statements almost exclusively from the natural sciences, especially from physics (p. 189); the examples are stated in idealized 'simple perceptual propositions' or "'elementary" propositions' (p. 189); there is an overly simple opposition between true and false statements postulated (p. 189) and an abstract and isolated subject of knowledge is presupposed (p. 204). In its abstract universalism this form of epistemology fails to be context sensitive (pp. 187-8) and, further, it presupposes, imperialistically, a false homogeneity (pp. 201, 206) with the 'often coercive view that we all see everything in the same way' (p. 201). In short: according to Code we are facing an epistemology which unduly constrains the concept of knowledge (p. 190). Code explicitly opposes the old positivist credo according to which knowledge is either scientific knowledge, or it is not knowledge at all' (p. 195). Against this, she advocates 'developing [...] "an epistemology of everyday life"' (p. xi) and denies the possibility of generalization for an epistemology based on scientific examples because of there being 'no reasons to assume and expect homogeneity across the physical and social world' (p. 206).

Whatever one thinks of the old positivist dream of a unified science based on physics or of the tasks an epistemology has to fulfil, it seems clear that Code's uneasiness with that kind of epistemology will not be relieved by simply changing the paradigms of what it means to know something or in changing the paradigmatic content of p. Taking your examples from everyday life instead of science will not get you any further as long as you continue to use, say, a propositional concept of knowledge. There is simply no guarantee that an epistemology based on everyday observational data does not yield abstract formulations and universalist claims of validity similar to the 'old' scientistic theory of knowledge (Kornblith [1999] is a good example for remaining abstract even with everyday life examples).

Furthermore, even if the charge were justified that scientistic epistemology unduly restricts the observable phenomena, it seems, in fact, that Code's central worry with such an epistemology lies elsewhere. For Code, the primary issue is, I think, the degree of abstraction of those theories, the fact that they can be modelled around the ' $S$ knows that $p$ ' formula. For in this formula - precisely because it is only a formula $-\mathrm{S}$ is indeed genderless, ahistorical, socially unlocated, disembodied and so on. That is what it means to be a placeholder, a variable, which the in itself meaningless letter ' $S$ ' represents. ${ }^{4}$ It is a completely different question whether such a formula is very informative concerning a random (or particular) instance of $S$ or of $p$, or whether it is useful to work with that kind of formula, given that $S$ had historically (i.e. contingently and not necessarily) been 
interpreted as being male. But it is exactly these questions that seem to be the real concern of Code and other feminist critiques of traditional epistemology. The concern is important. But one should be careful not to blur, at least not without argument, a feminist approach in history of science with a feminist approach in epistemology or philosophy of science.

Elsewhere, in her critique of naturalized epistemology (Code, 1996), Code has stated more clearly what she is after, namely a finely differentiated description of human epistemic activity: a description that attends very closely, scrutinizing the matter, metaphorically speaking, with a magnifying glass and giving concrete accounts of it, especially concrete accounts of S that, say, take S's gender into account. Although the direction that Code's own epistemic ideal points to is fairly clear, her formulations concerning a concrete epistemological programme remain vague. One thing, however, seems unavoidable, given this ideal: you have to pay the price of a more restricted possibility of generalization and/or to integrate a number of additional variables that could give an account of the claimed differentiated epistemic activities. This is what it would mean to take a view from somewhere and to make the 'some' transparent. The programme of epistemological contextualism for instance points in that direction, though one should note that gender-sensitivity is no primary concern of that approach.

But does this imply any relativism? Is restricting the scope of generalization or augmenting the number of variables the same as relativizing your claims to some framework? I don't think so. But let me consider first why, at all, the concept of relativism enters the discussion.

There seem to be relativistic tendencies in some of Code's claims. For instance, epistemic descriptions have to be context-sensitive (Code, 1995: 195, 201), they should take into account subjective factors (pp. 187, 188), there is no context-free truth (p. 197), there is no transcendent standpoint (p. 201) and 'knowledge is constructed in positions of varying power and

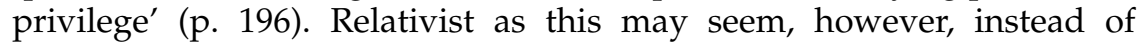
concluding that relativism is the position to be endorsed, we could simply give up the ideal of having epistemic descriptions that are unconditionally universalizable. As a result, there would be a multiplication of epistemic descriptions accounting simultaneously for more or less the same practices or domains with slight differences due to a weighting of the different concrete factors involved: that is, to differences due to the number and kind of involved variables. It would be a pluralistic account of knowledge. Pluralism, however, does not necessarily imply the incompatibility of those different concrete epistemic descriptions. You can have your context-sensitive descriptions and still be able to logically conjoin them with others or 'translate' them into a more abstract language. (Moore [1997] for instance, has worked out that line of argument; see also Haack, 1998.) The crucial point - in contrast to relativism - is precisely not to 
make the conjunctive claim that epistemic descriptions are justified only relatively to a framework or a context and that different frameworks are, ultimately, incommensurable. It is incommensurability that, in this view, decides whether you are dealing with a relativist position or not. ${ }^{5}$

Now, the remarkable thing about Code's position is that the concept of incommensurability is not mentioned in the text. ${ }^{6}$ And this, at least in my opinion, makes her concept of relativism rather woolly. Furthermore, there is one specific case where she explicitly dismisses relativism because it entails incommensurability. It is the (admittedly extreme) case of a culture A claiming that the earth is flat and culture B claiming that it is round: 'If such were indeed the inevitable result of endorsing relativism, it needs no argument to show that feminists, with other theorists of knowledge, would have to resist it' (Code, 1995: 202). But because, according to Code, such cases are rare, they are easily mastered with a 'politically informed "strategic universalism"' (p. 199). This 'both-andand-also-position', as I would call it, is termed 'mitigated relativism' elsewhere (Code, 1991: 251, 264, 320; Code, 1998: 75). By 'mitigated relativism', Code means that one should be relativist from case to case, but in extreme cases one would better adhere to universalism. In other words, this seems to be a case of part-time relativism.

This part-time relativism is odd, not only because of conceptual or consistency reasons but also because Code gives no explicit criteria for its application. In which cases, exactly, should one be a relativist and in which, a strategic universalist? Why is the case of flat earth vs round earth adherents such an obvious and imperative instance of a strategic universalism?

There are at least two remarks to be made on that point. First, although Code is harshly criticizing a scientistically narrowed form of epistemology, she acknowledges scientific achievements in various domains such as medicine, physics, biology, etc. The practical success and the evident usefulness of the applied sciences seem to count heavily against attempts to make implausible contrary claims. Therefore, the apparent practical success of the round earth account seems to be enough to rule out flat earth accounts. ${ }^{7}$ But one would nevertheless wish to have a normatively stronger rationale concerning the application of part-time relativism. Unfortunately, this is not to be found in Code. The second remark concerns a distinction that can most clearly be made at this point: the distinction between a relativist epistemology and a relativist rhetoric. It appears that Code's arguments should be appreciated more for their rhetorical than their epistemological value. What the rhetorical value amounts to can be better assessed after the discussion of the second cluster of arguments Code gives as reasons why feminists should be relativists, the so-called rebellious arguments, to which I now turn.

Although the rebellious arguments are related to the critique of the 
scientistic form of epistemology, the tone is strikingly different. It is defiant and often polemical. Code speaks of the 'discursive hegemony' (Code, 1995: 188, see also p. 195) wielded by the 'mainstream epistemology' (p. 189), its 'imperialistic epistemic practices' (p. 190, see also p. 201) and of 'boundaries' that are to be 'transgress[ed]' (p. 190). She accuses the post-positivist epistemology of an 'irrational reductivism' (p. 200) with 'totalizing impulses' (p. 206), which could be countered by 'adopting a relativist position' (p. 207). Most clearly in this contumacious rhetoric are statements where Code opts for relativism 'simply as a refusal of the universalist-objectivist alternatives' (p. 194).

Given that these kinds of rebellious expressions appear rather frequently in the text, I feel justified in seeing in them Code's basic motivations and reasons for claiming relativism on behalf of feminists. This view is supported by the tone of the text as well as the reference to Feyerabend's dictum that relativism is a 'weapon against intellectual tyranny' (p. 206). Although I sympathize with that contumacious stance and even consider a portion of it necessary to a feminist perspective not only in epistemology - after all, critique of ideology is one of the oldest feminist pursuits - I still doubt that it is a compelling, let alone sufficient, reason for (epistemological) relativism.

First, the refusal of a position does not in itself entail a new position. Rather, the negation sign makes the 'new' derivative from the 'old', rejected position. So Code's 'refusal of the universalist-objectivist alternatives' would lead her at most to an anti-universalist (anti-objectivist) position. But things are more complicated, because the rebellious arguments are not only directed against 'imperialist epistemic practices' that are equated with the universalist mainstream epistemology, but also and explicitly against the anti-relativism inscribed in that position. She wants to argue, Code says, against the 'caricature of relativism' (p. 186) resulting from the anti-relativist's, i.e. universalist's, presentation. But in going against an anti-relativist caricature of relativism, Code is, I claim, less the rebellious (epistemological) relativist than a deliberate (rhetorical) antianti-relativist, or, at least, she should be understood as such.

Presumably Code would even agree being called an anti-anti-relativist - at least the expression casually appears in her text. ${ }^{8}$ Being an acclaimed anti-universalist, and universalists being classically anti-relativists, she most certainly is an anti-anti-relativist as well. What Code possibly would not agree with is the thesis that the doubled prefix 'anti' is not dissolved without remainder by the law of double negation, but that it refers back to her anti-universalism.

Clifford Geertz, who coined the term 'anti-anti-relativism' (Geertz, 1989) reflected explicitly the relationship between the two prefixes. The double 'anti' before 'relativism' is, according to Geertz, an analogous construction to the double 'anti' before 'communism' in the time of US 
Senator McCarthy. Directed against the anti-communist hysteria of that time, an anti-anti-communist attitude is, however, far from representing a communist or a pro-Soviet attitude; in the same way, an anti-anti-abortion attitude does not imply that one takes abortion to be a wonderful thing.

In this frame, the double negative simply doesn't work in the usual way; and therein lies its rhetorical attractions. It enables one to reject something without thereby committing oneself to what it rejects. And this is precisely what I want to do with anti-relativism. (Geertz, 1989: 13)

If my interpretation of Geertz is correct, then doubling the prefix results in a kind of dynamic move that sets things in motion and prevents recourse to the age-old philosophical positions on an epistemological level. The first 'anti' is directed against the second 'anti', that is, against certain forms of the critique of relativism (i.e. anti-relativist arguments) without being committed to using relativist arguments per se. The goal is to disarm the danger associated with a completely overstated form of relativism, regularly pointing to a breakdown of rational argument when adjudicating over competing claims or theories or to the immoral or irrational state of 'anything goes'. To do this, that is to disarm the overstated consequences of relativism, it is not even necessary to defend relativism or to ground a relativist position: it is enough to point out the absurdity of the anti-relativist critique. The latter but not the former is exactly what Code is doing in recalling the distortions of the anti-relativist critique in her text (Code, 1995: esp. 186-91, 205; note, however, that even Code is not free of falling into the trap of distorting images herself in invoking the flat earth vs round earth case as an unwelcome consequence of relativism and, therefore, an instance of an imperative strategic universalism).

I asked in the beginning what could one's and in particular what could Code's reasons be to plead for relativism instead of joining the 'broader or improved objectivity' programme in feminist epistemology. As matters stand now, the plea for relativism and this 'programme' have much more in common than it seemed at first glance. The relationship is twofold and bidirectional.

On the one hand, it turns out that the feminist uneasiness with traditional epistemology, represented here through Code's position, calls for more finely differentiated descriptions of concrete epistemic practices and for a certain degree of contextualization. For this purpose, it is enough to give up the abstract ideal of objectivity inherited from the positivist strand in philosophy of science. But the mainly anti-universalist (or perhaps: anti-simplificationist or anti-abstractionist) desire for situating, contextualizing or concretizing epistemic descriptions works easily within the 'broader objectivity' programme. It is deeply committed to the 
'point of somewhere', representing the altered more complex concept of objectivity, and it accounts for it. Moreover, there is no need to weaken one's position with a part-time relativism by introducing strategic universalism.

On the other hand, it turns out that Code should be interpreted as pleading not for relativism but for anti-anti-relativism. This is something feminists could indeed take over from her. Only, instead of 'coming out' as relativists they might do well to come out as anti-anti-relativists. Thus, rather than ritually distance themselves from relativism and defend themselves with substantial arguments against charges of it, feminists could simply dismiss those charges as rhetorically overstated and being, in most of the cases, not relevant epistemologically.

\section{NOTES}

I would like to thank Henry Pickford for his help with the English version of the article.

1. See, for instance, Giere (1996) or Fricker (2000) for a so-called perspectival realism, explicitly denying any relativism. An early attempt to 'transform' the concept of objectivity without being committed to any form of relativism and, moreover, issuing far from a feminist context, is presented by Scheffler (1967). See also Suppe's (1974) account of Weltanschauungen approaches to scientific theories, which ends up in a rather far-reaching reformulation of the former strictly value-free approaches. For feminists arguing against the very concept of a feminist epistemology, see Haack (1993) and Pinnick (1994). For a feminist accusing other feminists of relativism, see Clough $(1998,2003)$.

2. If one is not explicitly interested in a specific form of relativism (e.g. moral relativism) or in a specialized debate, then the observation is unavoidable that there are just too many forms of relativism. For instance, Code (1995: 200) counts four forms of relativism; Martin Hollis and Steven Lukes (1982: 5-10), five forms; Ilkka Niiniluoto (1996: 139-57), 11 forms; Michael Krausz (1989: 2-3) mentions 16 possibilities to construct a form of relativism; Susan Haack (1998: 149-66) starts with more than nine forms, which are furthermore to be multiplied by a permutation factor; and Rom Harré and Michael Krausz (1996: vii) speak of a 'proliferation of varieties of relativism'. (This list is not exhaustive.)

3. The term 'incommensurability' was introduced into the sociology of science by Ludwik Fleck in 1935 (Fleck, 1999). But it became famous, not to say notorious, only in the post-positivist philosophy of science debate following Thomas Kuhn's and Paul Feyerabend's reintroduction of the term in 1962 (Kuhn, 1962; Feyerabend, 1962).

4. Cf. in this connection the consciously provocative question of Trettin (1995) whether gender as a parameter should be included in epistemology at all.

5. The argument of incommensurability as differentia specifica of relativism is developed in Hönig (forthcoming).

6. See especially pp. 192-3 and 196-9, where Code deals with charges of 
inconsistency of relativism without mentioning the incommensurability problem. In Code (1991) the problem is mentioned but, apparently, Code takes a Protagorean or pragmatist position in claiming that 'some knowledge is better than other knowledge' (Code, 1991: 4).

7. It is particularly odd that Code steps back from her relativist claim with such a simplifying and overstating characterization of relativism as it is given in the flat earth vs round earth account. Her declared aim had been to argue against a 'caricature of relativism that no self-declared, self-respecting relativist would endorse' (Code, 1995: 186). A more subtle account of relativism in terms of flat earth vs round earth accounts would certainly draw on the underdeterminacy thesis and the following possible empirical equivalence of theories. Therefore, the confrontation between culture A claiming the earth's flatness and culture B claiming the earth's roundness would be much more complex than the confrontation between those two incompatible statements about the earth's shape.

8. The term 'anti-anti-relativism' appears three times in Code's text: first in quoting from an essay of Clifford Geertz with that very title (Code, 1995: 187), second in the equation of 'a newly affirmed pro-relativist ... position' with 'anti-anti-relativism' (p. 194) and third in the description of the realms of interest for the (i.e. her) so-called 'anti-anti-relativist' (p. 202).

\section{REFERENCES}

Barwell, Ismay (1994) 'Towards a Defence of Objectivity', pp. 79-94 in K. Lennon and M. Whitford (eds) Knowing the Difference: Feminist Perspectives in Epistemology. London: Routledge.

Betzler, Monika (1998) “"Objektivität” als epistemische Norm feministischer Erkenntnistheorie', Deutsche Zeitschrift für Philosophie 46: 783-97.

Clough, Sharyn (1998) 'A Hasty Retreat from Evidence: The Recalcitrance of Relativism in Feminist Epistemology', Hypatia 13: 88-111.

Clough, Sharyn (2003) Beyond Epistemology: A Pragmatist Approach to Feminist Science Studies. Lanham, MD: Rowman and Littlefield.

Code, Lorraine (1991) What Can She Know? Feminist Theory and the Construction of Knowledge. Ithaca, NY: Cornell University Press.

Code, Lorraine (1995) 'Must a Feminist be a Relativist After All?', pp. 185-207 in Rhetorical Spaces: Essays on Gendered Locations. New York: Routledge.

Code, Lorraine (1996) 'What is Natural about Epistemology Naturalized?', American Philosophical Quarterly 33: 1-22.

Code, Lorraine (1998) 'How to Think Globally: Stretching the Limits of Imagination', Hypatia 13: 73-85.

Feyerabend, Paul (1962) 'Explanation, Reduction, and Empiricism', pp. 28-97 in H. Feigl and G. Maxwell (eds) Scientific Explanation, Space and Time. Minneapolis: University of Minnesota Press.

Fleck, Ludwik (1999) Entstehung und Entwicklung einer wissenschaftlichen Tatsache. Einführung in die Lehre vom Denkstil und Denkkollektiv. Frankfurt am Main: Suhrkamp.

Fricker, Miranda (2000) 'Feminism in Epistemology. Pluralism without Postmodernism', pp. 146-65 in M. Fricker and J. Hornsby (eds) The Cambridge Companion to Feminism in Philosophy. Cambridge: Cambridge University Press.

Geertz, Clifford (1989) 'Anti Anti-Relativism', pp. 12-34 in M. Krausz (ed.) 
Relativism: Interpretation and Confrontation. Notre Dame: University of Notre Dame Press.

Giere, Ronald N. (1996) 'The Feminism Question in the Philosophy of Science', pp. 3-15 in L. Hankinson Nelson and J. Nelson (eds) Feminism, Science and the Philosophy of Science. Dordrecht: Kluwer.

Gorham, Geoffrey (1995) 'The Concept of Truth in Feminist Science', Hypatia 10: 99-116.

Haack, Susan (1993) 'Knowledge and Propaganda: Reflections of an Old Feminist', Partisan Review 60: 556-64.

Haack, Susan (1998) 'Reflections on Relativism: From Momentous Tautology to Seductive Contradiction', pp. 149-66 in Manifesto of a Passionate Moderate: Unfashionable Essays. Chicago, IL: University of Chicago Press.

Hankinson Nelson, Lynn (1990) Who Knows: From Quine to Feminist Empiricism. Philadelphia, PA: Temple University Press.

Haraway, Donna (1991) 'Situated Knowledges: The Science Question in Feminism and the Privilege of Partial Perspective', pp. 183-201 in Simians, Cyborgs, and Women: The Reinvention of Nature. London: Routledge.

Harding, Sandra (1991) Whose Science Whose Knowledge: Thinking From Women's Lives. Milton Keynes: Open University Press.

Harding, Sandra (1993) 'Rethinking Standpoint Epistemology: What is "strong objectivity"?', pp. 49-82 in L. Alcoff and E. Potter (eds) Feminist Epistemologies. New York: Routledge.

Harding, Sandra (1995) "'Strong Objectivity": A Response to the New Objectivity Question', Synthese 104: 331-49.

Harré, Rom and Michael Krausz (1996) Varieties of Relativism. Oxford: Blackwell.

Hollis, Martin and Steven Lukes, eds (1982) Rationality and Relativism. Oxford: Blackwell.

Hönig, Kathrin (forthcoming) 'Im Spiegel der Bedeutung' - Über die Begründbarkeit von Relativismus.

Kornblith, Hilary (1999) 'The Epistemology of Science and the Epistemology of Everyday Life', Facta Philosophica 1: 21-37.

Krausz, Michael, ed. (1989) Relativism: Interpretation and Confrontation. Notre Dame: University of Notre Dame Press.

Kuhn, Thomas (1962) The Structure of Scientific Revolutions. Chicago, IL: University of Chicago Press.

Lloyd, Elisabeth (1995) 'Objectivity and the Double Standard for Feminist Epistemologies', Synthese 104: 351-81.

Lloyd, Elisabeth (1996) 'Science and Anti-Science: Objectivity and its Real Enemies', pp. 217-59 in L. Hankinson Nelson and J. Nelson (eds) Feminism, Science and the Philosophy of Science. Dordrecht: Kluwer.

Longino, Helen (1990) Science as Social Knowledge: Values and Objectivity in Scientific Inquiry. Princeton, NJ: Princeton University Press.

Moore, Adrian (1997) Points of View. Oxford: Clarendon Press.

Niiniluoto, Ilkka (1996) 'The Relativism Question in Feminist Epistemology', pp. 139-57 in L. Hankinson Nelson and J. Nelson (eds) Feminism, Science and the Philosophy of Science. Dordrecht: Kluwer.

Pinnick, Cassandra (1994) 'Feminist Epistemology: Implications for Philosophy of Science', Philosophy of Science 61: 646-57.

Scheffler, Israel (1967) Science and Subjectivity. Indianapolis: Hackett.

Suppe, Frederick (1974) 'The Search for Philosophic Understanding of Scientific Theories', pp. 3-232 in F. Suppe (ed.) The Structure of Scientific Theories. Urbana: University of Illinois Press. 
Trettin, Käthe (1995) 'Zwei Fragen zur feministischen Erkenntnistheorie', Feministische Studien 13: 95-106.

Kathrin Hönig trained in philosophy at the Freie Universität Berlin (Germany), University of Basle (Switzerland) and Pittsburgh University (USA). She achieved her PhD in philosophy in 2002 from the University of Basle. Her main areas of research are: philosophy of language, epistemology, philosophy of science and feminist theory and methodology. She is currently working on gender-neutral (allegedly) philosophical body-mind theories. Address: Universität Zürich, Roggenstr. 4, CH-8005 Zürich, Switzerland. [email: kathrin.hoenig@unibas.ch] 